It would be useless to apply to the old ladies of Rhubarb Hall, but we would advise our correspondent to address the Assistant Poor-Law Commissioner, and also his superiors at Somerset-house. From the recommendations which have lately been promulgated by the chief Commissioner on the important question of providing medical -attendance and medicine for the sick paupers, we are strongly inclined to believe that an application to the Commissioners might not prove unsuccessful.

\section{MR. KIERNAN'S DISCOVERY OF VARICOSE CAPILLARIES.}

\section{To the Editor of The Lancet.}

Sir:-Mr. Kiernan has called my attention to the following passage, which occurs in a recent publication of Dr. Hake, and as the fact therein stated is propounded as a recent discovery, he has appealed to me for my testimony on this point :-

"The new vessels do not shoot into albuminous or other deposit, as some have supposed, but proceed in the form of flocculi from a vascular base, become varicose, and again give off branches."

In answer to the appeal of Mr. Kiernan, and in common justice to that gentleman, I feel bound to declare that I have known of the existence of these vessels, in connection with carcinoma, for three years; that they were originally shown to me by $\mathrm{Mr}$. Kiernan ; that $I$ have mentioned them in $m y$ surgical lectures, at King's College, during the last two years, as the discovery of that gentleman; and that the language I used in describing them was "that these vessels shot into space, and not into any bed previously. prepared for them; and that I had seen such vessels shooting from the inner surface of the peritoneum."-I am your obedient servant,

New Burlington-street,

James M. Arnotr. Aug. 28, 1839.

\section{FOR ATTENTION AT APOTHE- CARIES' HALL.}

To the Editor of THE LANCET.

SIR :-The time is fast approaching when the registration books of the Hall will be opened again. .. May I beg of you to confer the favour upon medical.students of trying to induce the Society of Apothecaries to adopt some good mode of entering the regis- trations, instead of keeping them waiting in the courtyard of the Hall for more than three hours at a time, and, consequently, making them lose some of the lectures which they are obliged to pay for, and expected to attend.-I remain, Sir,

A Student of St. George's. August 19, 1839 .

\section{MR. MACKENZIE'S MEMORIAE.}

This memorial to the Senate of the University of London contained the following statement :-Mr. Mackenzie said that at his interview with $\mathrm{Mr}$. Kiernan, on the 25th of July, that gentleman told him that he had done very well in his examination; that, so far as he had learned, he bad done very well in forensic medicine; that $\mathrm{Mr}$. Bacot, as regarded his paper on surgery, had expressed a most favourable opinion respecting: it before the examiners. *** And $\mathrm{Mr}^{*}$. Mackenzie said that Mr. Kiernan "admitted that, in his opinion, the examiners had seriously erred, and expressed a hope that the division of the classes might yet be altered."

In relation to the latter sentence $\mathrm{Mr}$. Mackenzie has sent to us the following note :-

Sir:-As a passage in my memorial appears to have occasioned some misapprehension, I will thank you to insert the following statement:-Mr. Kiernan did not, in any part of his conversation with me assert that the examiners had seriously erred respecting the division of the classes, nor have I stated so in my memorial.-I have the honour to be, \&c.

University College, Aug. 23, 1839.

\section{FOREIGN HOSPITAL PRACTICE.}

\section{LA C THARITE.}

FALI FROM A HEIGHT.-INFLAMMATION OF THE SPINAL MAREOW.

JUNE 6. A locksmith, aged 23, was admitted to-day. Three days ago he fell from the second story, in consequence of his stepping upon a board which was inadequately supported. He remained unconscious for about ten minutes; afterwards he was able, although feeling rather stupified, to return to his work.' There is a slight wound of the scalp in front. The next day he felt great pain and stiffiness in the neck, and these have been increasing up to the present time. He supports his head with his two hands, and seems unwilling to try to hold it up without their assistance; he was bled to sixteen ounces.

In the course of the night he was delirious, but is quite tranquil and rational this 